5.

Derecho Tributario 



\title{
JURISPRUDENCIA RELEVANTE DE LA CORTE SUPREMA EN MATERIA TRIBUTARIA DEL AÑO 2016
}

[Relevant jurisprudence of the supreme court in tax matters of the year 2016]

\author{
Manuel Rodríguez VegA* \\ Universidad de Talca
}

\begin{abstract}
RESUMEN
ABSTRACT

En este trabajo se presentan algunos de los pronunciamientos más relevantes dictados por la Excelentísima Corte Suprema de Chile durante el año 2016 en materia tributaria, buscando resaltar aquellos que evidencian un cambio jurisprudencial en la materia que tratan $\mathrm{o}$, al contrario, demuestran el asentamiento de un determinado criterio en un tema particular en materia impositiva, con lo cual, en definitiva, se busca representar la evolución jurisprudencial del Máximo Tribunal durante dicho período.

Palabras clave

Jurisprudencia - Corte Suprema de Chile - Derecho Tributario.

This paper gathers some of the most relevant tax cases addressed by the Chilean Supreme Court during 2016. The cases are aimed to highlighted how certain all precedents have been disregarded by the Court and others have prevailed. Therefore, this paper is aimed to show how the Chilean highest court approach has developed regarding tax matters.

KEY WORDS

Jurisprudence - Supreme Court of Chile - Tax Law.

ReCIBIDO el 1 de noviembre de 2017 y APROBADO el 12 de mayo de 2018

* Abogado. Licenciado en Ciencias Jurídicas y Sociales por la Pontificia Universidad Católica de Chile. Magíster en Derecho por la Universidad de Talca. Doctor en Derecho por la Universidad de Chile. Profesor de Derecho Tributario de la Facultad de Ciencias Jurídicas y Sociales y de la Facultad de Economía y Negocios de la Universidad de Talca. Dirección postal: Santa Elena N²222, San Joaquín, Santiago de Chile. Email: manrodriguez@utalca.cl.
\end{abstract}




\section{INTRODUCCIÓN}

A diferencia de otras áreas del derecho, la cátedra chilena no ha dedicado suficiente esfuerzo al estudio y sistematización de la jurisprudencia de nuestros tribunales superiores en materia tributaria, empeño que, desde luego, resulta necesario emprender y, con especial énfasis, en relación a los fallos emanados de nuestra Corte Suprema, por el rol uniformador que explícita e implícitamente le conceden diversas disposiciones adjetivas de nuestro ordenamiento a dicho tribunal, lo que permitiría identificar los criterios asentados en sus sentencias en determinados asuntos, así como las situaciones que hacen excepción a los mismos y cuándo se presentan $y$, eventualmente, las contra excepciones que pudieren darse, todo ello originado por la diversidad de la casuística objeto de su conocimiento.

No debe pasarse por alto que, en la medida que se consolida una tendencia jurisprudencial, la Corte usualmente desestima volver a conocer latamente de la materia, desechando el recurso de casación en el fondo por la vía de declarar que adolece de manifiesta falta de fundamento, conforme lo prevé el artículo 782, inciso $2^{\circ}$, del Código de Procedimiento Civil ${ }^{1}$.

Emprender el aludido esfuerzo en el área del derecho tributario resulta ineludible por la apremiante necesidad de seguridad jurídica en este ámbito, en el que la lícita planificación de las actividades comerciales y financieras contempla siempre los efectos tributarios de las mismas, resultando por ende relevante para los contribuyentes en tal actividad, como también para el Servicio de Impuestos Internos en la fiscalización de las mismas, contar con claridad sobre la correcta aplicación de las normas procesales y sustantivas con incidencia en el área impositiva.

${ }^{1}$ Por ejemplo, al declarar que los plazos de prescripción establecidos en el artículo 200 del Código Tributario rigen para la acción de cobro de las multas cursadas por la Dirección del Trabajo que se tramitan conforme al procedimiento ejecutivo reglado en el Código Tributario ( $\mathrm{Rol} \mathrm{N}^{\circ} 32.094-14$ de 13 de abril de 2015, Rol N ${ }^{\circ}$ 5379-16 de 28 de marzo de 2016); no obstante lo anterior, resolviendo con previa vista de la causa, declaró en el Rol No 52.954-2016 de 28 de diciembre de 2016 que en la misma materia "cabe aplicar las normas de derecho común, en particular, lo dispuesto en el artículo 2515 del Código Civil, que señala que las acciones ejecutivas prescriben en tres años" (cons. $6^{\circ}$ ). Asimismo ha resuelto la improcedencia de accionar de prescripción ante los tribunales ordinarios mientras se siga adelante en contra del contribuyente un procedimiento ejecutivo ante Tesorería (Rol N ${ }^{\circ} 14.993-16$ de 28 de marzo de 2016, Rol No 16.285-16 de 28 de marzo de 2016, Rol No $16.353-16$ de 28 de marzo de 2016, Rol No 45.877-16 de 8 de agosto de 2016 y Rol No 49.683-13 de 17 de agosto de 2016). Y de la misma forma, en cuanto a la exención de impuestos a la renta de los excedentes entregados por la cooperativas a los socios originados en operaciones de éstos con aquéllas ( $\mathrm{Rol} \mathrm{N}^{\circ}$ 6280-15 de 27 de mayo de 2015). 
Con ese objeto entonces se exponen en este trabajo algunas materias en las que se aprecia, en algunos casos luego de un cambio de criterio, una consolidación jurisprudencial en un determinado sentido, contribuyendo de ese modo la Corte Suprema a la demandada unificación de la jurisprudencia y certeza jurídica en materia tributaria.

\section{Plazo RaZonable para tramitación DEL}

PROCEDIMIENTO GENERAL DE RECLAMACIÓN DEL TÍTULO II DEL

\section{LIBRO IV DEL CÓDIGO TRIBUTARIO}

En fallos dictados en los años 2014 y 2015 en las causas Rol N ${ }^{\circ} 5165$ 13 de 14 de abril de 2014 y Rol N 13.387-14 de 18 de mayo de 2015, respectivamente, la Corte Suprema había sostenido que el derecho de toda persona a ser oída con las debidas garantías y dentro de un plazo razonable, por un juez o tribunal competente, independiente e imparcial, establecido con anterioridad por la ley, en la sustanciación de cualquier acusación penal formulada contra ella, o para la determinación de sus derechos y obligaciones de orden civil, laboral, fiscal o de cualquier otro carácter, que consagra el artículo $8 \mathrm{~N}^{\circ} 1$ de la Convención Americana de Derechos Humanos, y que resulta imperativo para los jueces nacionales en virtud del mandato establecido en el inciso $2^{\circ}$ del artículo $5^{\circ}$ de la Constitución Política de la República, en el caso del procedimiento general de reclamación tributaria que regula el Título II del Libro IV del Código Tributario, se estima que dicho plazo razonable corresponde al de seis años de prescripción extraordinaria que trata el artículo 200, inciso $2^{\circ}$, del Código Tributario, lo que fundamenta en que "si para el legislador tributario el interés fiscal en la recaudación de impuestos sólo justifica, en términos generales, un periodo de seis años como espacio temporal máximo por el que puede extenderse el estado de incertidumbre que significa para el contribuyente la indeterminación sobre el proceder de la Administración en relación a si liquidará o no diferencias de impuestos, plazo que incluso ya considera el supuesto de que la deuda provenga de la mala fe o incluso de ilícitos penales perpetrados por el contribuyente, no puede sino colegirse que a falta de texto legal en contrario, dicho interés fiscal no puede justificar tampoco que se prolongue por un periodo superior a esos seis años el estado de incertidumbre de la situación fiscal y patrimonial del contribuyente, después que éste reclama válidamente ante el órgano jurisdiccional para que se pronuncie sobre la legalidad o validez de la liquidación que le ha sido comunicada por el Servicio" (cons. $11^{\circ}$ del Rol No 5165-13 y cons. $12^{\circ}$ del Rol N 13.387-14).

De ese modo, concluye la Corte, "un procedimiento de reclamación que se extiende más allá de un sexenio a partir del reclamo oportunamente 
interpuesto y cumpliendo los requisitos del artículo 125 del Código Tributario, más aún si le antecede otro intervalo de igual duración correspondiente a la etapa de fiscalización, deviene en una violación de las garantías judiciales del contribuyente que reconoce la referida Convención, por cuanto importa someterlo a una carga que perpetúa la indefinición de su situación fiscal y patrimonial, en una continua vulneración de su derecho a obtener un pronunciamiento jurisdiccional definitivo respecto a su requerimiento, sea éste favorable o desfavorable" (cons. $11^{\circ}$ del Rol No $5165-13$ y cons. $12^{\circ}$ del Rol No 13.387-14).

En los fallos examinados la Corte fija dicho plazo máximo para la tramitación del procedimiento de reclamación, con abstracción de los motivos particulares por los cuales la dilación de los mismos se hubiese producido y, de esa manera, para esas decisiones no resulta determinante si la demora es imputable o no al órgano jurisdiccional o al Servicio de Impuestos Internos, ni tampoco considera cuál ha sido la conducta del contribuyente para evitar o acotar tal retraso en la sustanciación del proceso. Sin embargo, el efecto sustantivo de la fijación de tal término no viene dado, según tales pronunciamientos, por la invalidación de las actuaciones procesales posteriores al mismo -pues ello equivaldría que el mismo fallo de la Corte Suprema se vería afectado por esa nulidad-, sino porque a contar de dicho hito temporal, se reanuda el cómputo de la prescripción, el que se hallaba suspendido por efecto de la interposición del reclamo conforme a lo dispuesto en los artículos 201, inciso $5^{\circ}$, y $24^{\circ}$, inciso $2^{\circ}$, del Código Tributario (cons. $12^{\circ}$ del Rol N ${ }^{\circ} 5165-13$ y cons. $13^{\circ}$ del Rol No 13.387-14) y, de esa manera, ambos fallos acogen la excepción de prescripción opuesta no en el reclamo, sino durante el desarrollo de alguna de las instancias del juicio.

En el aspecto recién mencionado, esto es, en la fijación de un plazo máximo único para la tramitación del procedimiento de reclamación, es en el que se observa un cambio de criterio por parte del Máximo Tribunal en la sentencia dictada en la causa Rol No37.181-15 de 29 de noviembre de $2016^{2}$, en la que ahora sostiene que discernir si se vulnera o no

${ }^{2}$ Si bien tal modificación ya se anunciaba en sentencias previas de la Corte Suprema, en éstas se rechazó en definitiva la infracción al artículo $8 \mathrm{~N}^{\circ} 1$ la Convención Americana de Derechos Humanos sin entrar al análisis particular de los factores que determinarían si la misma se produce. Así en la sentencia Rol N²1.647-14 de 10 de junio de 2015 se desestima por constituir una alegación nueva del proceso, vertida sólo en el desarrollo de la vista del recurso de apelación, y porque el ejercicio de ponderación de los referidos elementos no resultaba posible en el caso de la especie, desde que no se demostró en el juicio la presencia de esas mismas circunstancias. En la sentencia Rol N ${ }^{\circ} 16.644-14$ de 10 de septiembre de 2015, se niega la infracción 
el derecho a ser oído en un plazo razonable en el procedimiento general de reclamación tributaria, debe dilucidarse siguiendo los criterios que ha seguido la doctrina instaurada por la propia jurisprudencia emanada de los organismos internacionales competentes, esto es, complejidad del asunto, diligencia de las autoridades judiciales, y actividad procesal del interesado ${ }^{3}$. $\mathrm{Al}$ respecto declaró la Corte que "como ha sostenido antes esta Corte en las causas Rol No 21.647-2014 de 10 de junio de 2015 y Rol No 16.644-2014 de 10 de septiembre de 2015, en el estado actual del debate jurídico no cabe duda que los preceptos de la Convención Americana de Derechos Humanosy, más precisamente, la garantía de ser juzgado dentro de un plazo razonable, tienen aplicación directa por estar incorporada al ordenamiento jurídico nacional luego de su publicación en el Diario Oficial el 5 de enero de 1991, de acuerdo con lo prescrito en el inciso $2^{\circ}$ del artículo $5^{\circ}$ de la Constitución Politica de la República, que establece como deber de todo órgano del Estado respetar y promover los derechos esenciales que emanan de la naturaleza humana garantizados por los tratados internacionales ratificados por Chile y que se encuentren vigentes. Esa garantía, a pesar de estar contenida en una norma que alude a la determinación de los derechos y obligaciones de orden civil, laboral, fiscal o de cualquier otro carácter, ciertamente tiene una mayor relevancia en el orden penal, puesto que en los procesos de esa naturaleza es el Estado el que dirige la acción en contra del sujeto a quien se imputa la vulneración de bienes jurídicos trascendentes protegidos por el ordenamiento jurídico, circunstancia que justifica dotar al ciudadano de una adecuada barrera de protección contra los excesos en la persecución criminal. La importancia de dotar al sujeto pasivo de la pretensión penal de garantías procesales se puede apreciar en las restantes disposiciones del párrafo pertinente de la Convención Americana de Derechos Humanos, que son aplicables mayoritariamente en ese ámbito. Al contrario, en el proceso de autos es un contribuyente quien ejerce una acción dirigida en contra de un órgano del Estado, reclamando la intervención judicial para la resolución de una cuestión de orden tributario, la que debe ser analizada con especial cuidado en cuanto al aspecto que se indica a continuación. Como se indicó también en los fallos recién citados, no es posible soslayar la circunstancia cierta de que tal precepto carece de una regla concreta de aplicación, esto es, no

argüida por el recurrente, atendido que el ejercicio de ponderar los elementos que determinarían una dilación inexcusable no resultaba posible por la circunstancia procesal de haberse suspendido la prescripción por la interposición del reclamo, cuanto porque el mérito de autos no lo motivaba según se desprendía de la lectura del fallo, sin perjuicio de tener presente además la Corte que parte de la doctrina lo estima improcedente en el ámbito de un recurso de derecho estricto como lo es el de casación.

${ }^{3}$ Los fundamentos de este fallo en sus líneas principales coinciden con el voto de minoría de la sentencia de la Corte Suprema Rol No 5165-13 de 14 de abril de 2014. 
contiene la determinación de lo que debe entenderse como un plazo razonable. En este sentido y ante la detección de esta carencia, la aplicación del principio queda entregada a la determinación del intérprete judicial, quien ha de tener presente las circunstancias del caso, debiendo establecer la concurrencia de hechos que obliguen a entender que ha tenido lugar una dilación inexcusable, actividad para la cual deben considerarse aspectos tales como la complejidad del asunto, diligencia de las autoridades judiciales, y actividad procesal del interesado, tal como ha señalado el propio Sistema Americano de Protección a los Derechos Humanos (Caso Genie Lacayo Vs. Nicaragua, Sentencia de 29 de enero de 1997; Caso Vargas Areco Vs. Paraguay, Sentencia de 26 de septiembre de 2006 y Caso Escué Zapata Vs. Colombia, Sentencia de 4 de julio de 2007)" (cons. $\left.3^{\circ}\right)^{4}$.

Añadió este último fallo, para desestimar la fijación de un plazo unívoco para el término del procedimiento general de reclamación que, "de otra forma, lo resultante no sería un juicio acerca del plazo máximo por el que pudo razonablemente diferirse el procedimiento de reclamación incoado por el contribuyente (...) sin vulnerar la mencionada garantía judicial, sino el reconocimiento de un tiempo máximo en el que perentoriamente debe sustanciarse y resolverse todo procedimiento de reclamación, de aplicación general y abstracta, prescindente por tanto de las circunstancias del caso particular y de las dimensiones de análisis antes referidas, en algo similar al establecimiento de un plazo de caducidad. Una declaración de ese tipo no es función de este Tribunal en nuestro sistema jurídico, sin perjuicio del rol que como Corte de Casación deba cumplir en la elaboración de una jurisprudencia uniforme en

${ }^{4}$ Estos argumentos son reiterados posteriormente en el fallo dictado en la causa Rol No 11.852-2015 de 6 de diciembre de 2016, pero dictaminando que tal ejercicio de ponderación no resultaba posible en la especie "por cuanto no se han establecido en la decisión recurrida las premisas fácticas necesarias para evaluar las condiciones del procedimiento a la luz de lo previsto en la Convención Americana de Derechos Humanos, premisas que no pueden incorporarse al no haberse denunciado la vulneración de las normas reguladoras de la prueba. Por lo demás, como se dijo, el plazo razonable para el juzgamiento es un concepto jurídico indeterminado que carece de delimitación legal, de modo que no existen requisitos concretos a revisar por este tribunal de casación y que le permitan constatar la eventual vulneración del artículo 8 del citado tratado internacional. Sin perjuicio de tener presente, además, que parte de la doctrina lo estima improcedente en el ámbito de un recurso de derecho estricto como lo es el de casación. De esta manera, se impone el rechazo del arbitrio en examen". Asimismo, en la causa Rol $\mathrm{N}^{\circ}$ 41.099-2016 de 26 de diciembre de 2016, si bien la Corte ratifica los criterios en base a los que debe discernirse la infracción a la garantía en comento, rechaza el recurso por no haber sido tal alegación planteada por el contribuyente ante los tribunales de la instancia. 
torno a los factores o elementos que los tribunales deben ponderar al resolver conflictos concretos como el de autos" (cons. $4^{\circ}$ ).

Luego la Corte se aboca al estudio de los elementos que en su parecer son determinantes para enjuiciar si ha habido o no una infracción al derecho a ser oído en un plazo razonable, no considerando en el caso ahí conocido como tal la materia sobre la que recayó la controversia (rechazo de gastos), pero sí la diligencia de las autoridades judiciales, que en ese caso anularon el procedimiento por haber sido llevado por un funcionario sin jurisdicción, estimando que tal actuación que ocasionó la dilación del juicio se realizó precisamente para resguardar o en aplicación del debido proceso (cons. $7^{\circ}$ ). En lo concerniente a la actividad procesal del contribuyente, la Corte tiene en cuenta que no se estableció en el fallo de la instancia que el reclamante hubiera efectuado alguna petición o actuación que evidenciara que la dilación del proceso le estuviese causando algún perjuicio grave en sus intereses, pues ninguna protesta formalizó por la tramitación del juicio ante autoridad sin facultades jurisdiccionales, y ninguna solicitud realizó para instar por su pronta terminación mediante las herramientas que la ley procesal le otorga para dicho fin (cons. $8^{\circ}$ ). Finalmente, en lo que atañe a los efectos o perjuicios que la dilación de la contienda significó para el contribuyente, la Corte consigna que éste siempre estuvo a resguardo del cobro de los impuestos adeudados por disposición del artículo 24, inciso $2^{\circ}$, del Código Tributario, encontrándose además autorizado para solicitar tanto al tribunal de alzada como a la misma Corte Suprema, la suspensión del cobro de los impuestos objeto de las liquidaciones, conforme al artículo 147 , inciso $6^{\circ}$, de la misma codificación (cons. $\left.9^{\circ}\right)^{5}$.

${ }^{5}$ Cabe mencionar que la Corte, al terminar el año en estudio, en la causa Rol No 28.604-2016 de 28 de diciembre de 2016 vuelve sobre el criterio expresado en los años 2014 y 2015, antes referido, pero esta vez en relación a un procedimiento ejecutivo de cobro de impuestos, casando de oficio el fallo impugnado y declarando "Que no es posible soslayar que consideraciones afincadas en el respeto a las normas constitucionales y de derecho internacional citadas, exigen que la acción de la justicia sea rápida y oportuna, tanto en escuchar a los justiciables, como en zanjar los problemas puestos en su conocimiento, sean ellos del ámbito civil o penal, debiendo resolverse el conflicto en un plazo razonable, esto es, ajustado a la razón. En tal perspectiva, no puede aceptarse, en razón de la antedicha normativa, que el pleito ejecutivo se extienda por más de dos décadas, plazo considerado desde la data de exigibilidad de los impuestos en cobro hasta la fecha de expedición de este fallo; lo que aparece como contrario a toda lógica y por cierto a las citadas disposiciones internacionales, con evidente conculcación de las garantías del contribuyente reconocidas por tales normas. El deber de respetar y promover el aludido derecho impone optar por aquella interpretación que, de manera mejor y más completa, resguarde y concrete tal garantía, cuestión que no se logra dando aplicación, únicamente, a la ley positiva del ordenamiento interno, pues ello importaría someter al contribuyente y parte ejecutada en este procedimiento a una carga que perpetúa la indefinición de su 
Por otra parte, no puede dejar de observarse que el que la Corte $\mathrm{Su}$ prema, conociendo de un recurso de casación se haya pronunciado sobre el fondo de una alegación que trata de la infracción de disposiciones constitucionales o de Tratados Internacionales suscritos por Chile que reconocen garantías fundamentales, en sí asienta o consolida una nueva línea jurisprudencial de dicho Tribunal $^{6}$, el que hasta fallos recientes había sostenido que mediante el recurso de casación en el fondo no se puede atacar la errónea aplicación o inaplicación de una norma constitucional. Así en causa Rol No 27.783-14 de 23 de diciembre de 2015, en el que se señala que "en lo que atañe a denuncias por infracción a normas de rango constitucional, por regla general resulta improcedente fundar una casación en el fondo en este tipo de disposiciones, toda vez que por ellas se establecen principios o garantías de orden genérico, que normalmente tienen su desarrollo en preceptos legales" (cons. $\left.30^{\circ}\right)^{7}$, e incluso con posterioridad a los fallos antes comentados vuelve a expresar en la causa Rol No 26.905-2015 de 28 de noviembre de 2016 que "en lo que se refiere a la infracción de los artículos 6 y 7 de la Carta Fundamental, cabe consignar que como lo ha sostenido reiteradamente esta Corte, resulta improcedente fundar una casación en el fondo en denuncias por contravención a normas de rango constitucional, toda vez que por ellas se establecen principios o garantías de orden genérico, que normalmente tienen su desarrollo en preceptos legales, como sucede en la especie. En el presente caso, los citados artículos 6 y 7, contienen principios y derechos de carácter general, cuya aplicación práctica queda entregada a los tribunales a través de las normas de naturaleza sustantiva y adjetivas previstas en los Códigos Tributario y Civil, respectivamente" (cons. $3^{\circ}$ ).

situación fiscal y patrimonial, continuando interminablemente expuesto a la realización de sus bienes ante la inactividad del ente encargado de llevar adelante el cobro de lo adeudado, inactividad que por lo demás no ha sido justificada y sin que, por otro lado, se haya atribuido al ejecutado alguna maniobra dolosa para ocultar sus bienes o entorpecer o dilatar el procedimiento de ejecución. En ese sentido, resulta contradictorio que la máxima prescripción que contempla nuestro Código Civil opere al vencimiento del término de diez años y, en cambio, la extinción de la pretensión fiscal pueda requerir un mayor plazo y encontrarse en suspenso indefinidamente, tornándose, en los hechos, en imprescriptible, sin fundamento legal' (cons. $7^{\circ}$ ).

${ }^{6}$ En la misma línea, el Rol № 21.647-14 de 10 de junio de 2015.

7 Del mismo modo, en Rol N 1917-2006 de 5 de septiembre de 2006, Rol No 2676-2011 de 10 de junio de 2011 y Rol N 6879-13 de 21 de julio de 2014. 
III. COMPETENCIA DE LOS TRIBUNALES TRIBUTARIOS Y ADUANEROS PARA CONOCER Y RESOLVER LA ACCIÓN DE NULIDAD DE DERECHO PÚBLICO RESPECTO DE ACTUACIONES ADMINISTRATIVAS DEL SERVICIO DE IMPUESTOS INTERNOS PREVIAS AL PROCEDIMIENTO JURISDICCIONAL

En el último tiempo la Corte Suprema ha conocido de diversos recursos de casación en los que se discute la competencia de los Tribunales Tributarios y Aduaneros para conocer de los incidentes de nulidad recaídos sobre actuaciones del Servicio de Impuestos Internos anteriores al inicio del procedimiento general de reclamación tributaria, peticiones que usualmente se sostienen en defectos formales de la citación o liquidación o por la ausencia de alguna actuación administrativa que acarrea la nulidad de las subsiguientes, como por ejemplo, la ausencia de firma del fiscalizador en el Rol No 12.874-2015 de 7 de diciembre de 2016; insuficiente fundamentación en el Rol No 27.319-14 de 18 de agosto de 2015 -en relación a la liquidación-y en el Rol No 12.874-2015 de 7 de diciembre de 2016 -respecto a la citación, alegándose consecuentemente también la nulidad de liquidación por falta de citación previa conforme al artículo 21 del Código Tributario-; falta de notificación en el Rol No 16.013-13 de 20 de agosto de 2014 en relación a la citación-; y nulidad de la Resolución que crea Departamento al interior del Servicio de Impuestos Internos que practica la liquidación en el Rol No 6879-13 de 21 de julio de 2014.

En esta materia la Corte Suprema ha venido sosteniendo en varias sentencias que los Tribunales Tributarios y Aduaneros no tienen competencia para conocer el asunto en estudio. Así ha declarado en el Rol No 6879-13 de 21 de julio de 2014 que "la competencia para conocer de las acciones de nulidad de derecho público se encuentra entregada a los tribunales ordinarios de justicia en razón de la materia, según se desprende de los artículos 38 inciso segundo de la Constitución Política de la República y 3 del Código de Procedimiento Civil. De esta manera, no es procedente alegar la nulidad de los actos fundantes de un juicio tributario, porque la competencia de esos tribunales se reduce a conocer del reclamo de ilegalidad de liquidaciones tributarias" $\left(\text { cons. } 3^{\circ}\right)^{8}$. Esta doctrina ha sido confirmada durante el año 2016 por el

${ }^{8}$ En la sentencia dictada en el Rol No 23.544-14 de 18 de agosto de 2015, no se emite un pronunciamiento de fondo, al expresar que "aunque se estimare que los jueces del grado son competentes para pronunciarse sobre la nulidad promovida por el contribuyente en su reclamo en virtud de la regla de extensión contemplada en el artículo 111 del Código Orgánico de Tribunales, aplicable al caso sub lite por remisión del artículo 2 del Código Tributario, la invalidación del fallo y dictación de la sentencia de reemplazo que la ley impone no resulta posible toda vez que en autos no se han asentado aspectos de 
Máximo Tribunal al expresar en el Rol No $18.136-15$ de 12 de octubre de 2016 que el fallo impugnado explica que "el rechazo del incidente de nulidad se asila en que la competencia para conocer y resolver las acciones de nulidad de derecho público está entregada a los tribunales ordinarios de justicia en razón de la materia, con arreglo a los artículos 38, inciso $2^{\circ}$, de la Constitución Politica de la República y $3^{\circ}$ del Código de Procedimiento Civil, de manera que el tema incide en una cuestión propia de un juicio ordinario y no de una reclamación tributaria (... ) Que a este respecto conviene destacar que tal aserto resulta del todo armónico con lo sostenido reiteradamente por esta Corte, en orden a que la nulidad de derecho público no puede ser conocida en esta instancia, toda vez que la Carta Fundamental y la ley entregan a los tribunales ordinarios la potestad de conocerla y fallarla, por lo que los jueces del grado han efectuado una correcta adaptación de la normativa que se dice violentada y entonces queda desprovista de asidero este acápite invalidatorio" (cons. $3^{\circ}$ y $\left.4^{\circ}\right)^{9}$.

Cabe destacar, como se desprende de lo que se viene exponiendo, que este asunto generalmente ha sido sometido al conocimiento y decisión de la Corte Suprema por la vía del recurso de casación en el fondo y sólo una vez mediante el recurso de casación en la forma. En las oportunidades en que se ha planteado a través del recurso de nulidad sustantivo, la Corte no ha hecho cuestión a la utilización de ese arbitrio en vez del de carácter formal, salvo en la causa Rol No 27.319-14 de 18 de agosto de 2015, en la que, aun cuando se rechaza el recurso por defectos formales en su planteamiento, apuntó que "importa dejar constancia que todas aquellas cuestiones que tienen relación con la competencia del tribunal constituyen alegaciones cuya naturaleza atiende más bien a un vicio de invalidación formal, que no fue promovido en este caso" (cons. $4^{\circ}$ ).

En la oportunidad en que la controversia en análisis fue llevada ante la Corte mediante el recurso de casación en la forma en el Rol N ${ }^{\circ} 16.013$ -

hecho que permitan la declaración de invalidez que se propugna, los que-de acuerdo a los fundamentos hechos valer oportunamente- tienen una dimensión fáctica cuya existencia y reconocimiento es un presupuesto esencial para acceder a lo pedido, conforme lo prescribe el artículo 785 del Código de Procedimiento Civil' (cons. $5^{\circ}$ ).

9 Esta doctrina se confirma en el Rol No 12.874-2015 de 7 de diciembre de 2016, en el que precisamente se citan los fallos arriba extractados. En el Rol N ${ }^{\circ}$ 26.905-2015 de 28 de noviembre de 2016, dos Ministros previnieron, respecto del capítulo de casación fundado en la nulidad de derecho público de las liquidaciones reclamadas, que sólo tuvieron presente para desecharlo, que "una pretensión como la indicada, que tiene relación con la validez de un acto administrativo, no forma parte de la órbita de competencia del Tribunal Tributario, que se limita al conocimiento de las materias propias de la especialidad, correspondiendo a los tribunales ordinarios hacerse cargo de ese planteamiento y resolver lo pertinente". 
13 de 20 de agosto de 2014, se alegó la causal $N^{\circ} 1$ del artículo 768 del Código de Procedimiento Civil, al estimar el recurrente que la sentencia -que acogió el incidente de nulidad- había sido pronunciada por un tribunal incompetente. El fallo que resuelve este arbitrio no se pronuncia sobre la competencia discutida, dado que lo desestima por la falta de la preparación que demanda el artículo 769 del Código de Procedimiento Civil. No obstante esto último, resulta interesante destacar que la Corte considera que para entender que se ejercieron oportunamente y en todos sus grados los recursos establecidos por la ley, no basta que el Servicio de Impuestos Internos -recurrente en la causa- en la contestación al traslado concedido por la interposición del incidente de nulidad, pida el rechazo del incidente -como lo hizo en el caso en referencia- pues ello importa reconocer que el Tribunal Tributario y Aduanero tiene competencia para pronunciarse sobre la validez de la actuación cuestionada por el contribuyente, debiendo en cambio haber solicitado que ese juzgado "se abstenga del conocimiento del incidente de nulidad planteado por el contribuyente y remita los antecedentes al tribunal de letras competente para conocer y decidir esta cuestión accesoria. Al contrario, como se comprobó recién, el Servicio desarrolla diversos argumentos destinados a afianzar su petición de rechazo del incidente de nulidad, siendo la incompetencia del Tribunal sólo uno más de los enunciados, todo lo cual revela de manera patente, que el Servicio de Impuestos Internos no controvirtió adecuadamente la competencia del Tribunal Tributario y Aduanero de la Región del Bío-Bio para fallar el incidente en comento, pues al solicitar su rechazo por razones de fondo, necesariamente admitió que dicho Tribunal ostentaba competencia para pronunciarse sobre el mismo" (cons. $4^{\circ}$ ).

Por último, cabe mencionar que en algunos procesos el Servicio de Impuestos Internos no ha controvertido ante la Corte Suprema la competencia del Tribunal Tributario y Aduanero para conocer la solicitud de invalidación de una actuación administrativa previa al procedimiento jurisdiccional de reclamación, sino que únicamente ha cuestionado el fundamento de la invalidación pretendida -en general, la carencia de motivación en las liquidaciones o resoluciones-, derivado de lo cual la Corte tampoco ha abordado ese punto, limitándose a resolver sobre lo discutido por las partes, así en la sentencias dictadas en el Rol No 16.588-2014 de 5 de mayo de 2015, Rol No 15.301-14 de 21 de julio de 2015, Rol $N^{\circ}$ 9432-15 de 24 de mayo de 2016, Rol No 9966-2015 de 12 de julio de 2016 y Rol No 36.489-15 de 24 de octubre de 2016. En este último fallo la Corte precisamente observa que "el reclamante, con la prueba rendida en el juicio (...) desvirtuó la 'validez' de la impugnación del Servicio, atacando los defectos de forma de ésta, atendida la ausencia de fundamentación de su 
resolutivo. Cabe reparar que el Servicio no ha cuestionado en su arbitrio la competencia de la jurisdicción tributaria para pronunciarse en este procedimiento general de reclamación sobre este punto", pero además agrega que esa omisión "resulta concordante, por lo demás, con el mismo texto del citado artículo 21, el que permite demandar la 'nulidad' de la impugnación mediante dicho procedimiento, precepto que además no distingue entre los motivos de forma -como la falta de fundamento, por ejemplo-y de fondo que pueden conducir a desvirtuar la impugnación del Servicio" (cons. $4^{\circ}$ ), con lo que pareciera exceptuar expresamente dentro de las actuaciones administrativas del Servicio previas al inicio del procedimiento de reclamación cuya nulidad se puede perseguir en éste, a la liquidación.

\section{Facultades del SERViCiO DE IMPUESTOS INTERNOS PARA DENEGAR UNA SOLICITUD DE DEVOLUCIÓN DE PAGO PROVISIONAL MENSUAL}

La Corte Suprema consolidó durante el año 2016 su doctrina por la cual sostiene que no obstante se presenten los supuestos previstos en el artículo 97 de la Ley sobre Impuesto a la Renta, esto es, que la suma de los impuestos anuales resulte inferior al monto de los pagos provisionales reajustados, el Servicio de Impuestos Internos podrá denegar su devolución si existieron observaciones o cuestionamientos no aclarados ante dicho Servicio en la determinación de su renta líquida imponible.

Así ha señalado en el Rol No 26.914-15 de 22 de septiembre de 2016 (cons. $3^{\circ}$ ) que "la cuestión central a resolver es si, por haber presentado la reclamante una solicitud de devolución de PPM, el Servicio se encontraba constreñido a la erogación correspondiente dentro del plazo de treinta días, aún cuando la declaración de impuestos respectiva le merezca reparos. Sobre este tópico, el artículo $8^{\circ}$ bis letra b) del Código Tributario establece un principio general, en cuanto prescribe que '...constituyen derechos de los contribuyentes, los siguientes: $2^{\circ}$ Derecho a obtener en forma completa y oportuna las devoluciones previstas en las leyes tributarias, debidamente actualizadas.' Sobre este derecho y su relación con las facultades de fiscalización, cabe considerar que el artículo 59 del mismo código dispone que 'Dentro de los plazos de prescripción, el Servicio podrá examinar y revisar las declaraciones presentadas por los contribuyentes.' En cuanto a la devolución que incida en los impuestos a la renta, el artículo 97 de la ley del ramo indica que 'El saldo que resultare a favor del contribuyente de la comparación referida en el artículo 96, le será devuelto por el Servicio de Tesorerias dentro de los 30 días siguientes a la fecha en que venza el plazo normal para presentar la declaración anual del impuesto a la renta.' El aludido artículo 96 prescribe, a su turno, que 'Cuando la suma de 
los impuestos anuales a que se refieren los artículos anteriores, resulte superior al monto de los pagos provisionales reajustados en conformidad al articulo 95, la diferencia adeudada deberá reajustarse de acuerdo con el artículo 72 y pagarse en una sola cuota al instante de presentar la respectiva declaración anual. Estas reglas inciden en el derecho del contribuyente al reintegro de las cantidades enteradas por concepto de PPM, siempre que medie un saldo a favor, luego de determinados los tributos a solucionar. De esta manera, el resultado surge después de comparados los pagos realizados con el cálculo del impuesto a la renta, operaciones reguladas por los artículos 84 y siguientes de la Ley sobre Impuesto a la Renta, por una parte, y los artículos 29 y siguientes del mismo cuerpo legal, por la otra. Tal estimación, efectuada por el contribuyente en su declaración de impuestos, no es inamovible, desde que con independencia del resultado que éste consigne en el formulario pertinente, sus actuaciones están sujetas a la eventualidad de una fiscalización del Servicio de Impuestos Internos y, por ende, no es dable discurrir de la preceptiva invocada en el recurso, que el ente fiscalizador esté compelido a desembolsar los gastos pedidos en la declaración de impuesto a la renta que le provoquen dudas acerca de su precisión o veracidad, porque tal derecho no puede entenderse consolidado sin una fiscalización o revisión que ratifique su exactitud. En estas condiciones el Servicio de Impuestos Internos conserva, respecto de las declaraciones de impuesto en las que se le requiere la devolución de especificas sumas satisfechas por un contribuyente por concepto de PPM, iguales facultades que aquellas en que se delimita el pago de impuesto, y queda habilitado para ejercitar sus atribuciones dentro de los plazos generales de prescripción. Es asi como el articulo 97 de la ley del ramo no se trata de una norma imperativa que concede un término perentorio de 30 dias para practicar la restitución de las cantidades pedidas, ya que el precepto supone la inexistencia de observaciones a la declaración de impuesto o que tal comparación cuente con la conformidad del Servicio, y en ningún caso constituye una derogación de las prerrogativas generales de fiscalización que le proporciona su ley orgánica" 10.

Esta doctrina ha sido complementada en el fallo del Rol No35.496-15 de 12 de diciembre de 2016, al señalar que "no es condición para desestimar la devolución de PPM el que se haya cuantificado un impuesto a pagar en una Liquidación dictada conjunta o posteriormente a la Resolución que rechaza la devolución, pues la ley no ha establecido tal dependencia de esas actuaciones administrativas-Resolución y Liquidación-, no obstante que tanto el rechazo a la devolución contenida en la resolución como la liquidación de impuestos

${ }^{10}$ En igual orientación, en el Rol No 32.359-14 de 4 de noviembre de 2015, Rol $\mathrm{N}^{\circ} 1115-15$ de 29 de diciembre de 2015, Rol No 3319-15 de 17 de marzo de 2016 y Rol No 35.496-15 de 12 de diciembre de 2016. 
se basen en el mismo supuesto, esto es, el incorrecto acertamiento del resultado tributario por el contribuyente $y$, de ahi, que ambas actuaciones sean reclamables autónomamente como se desprende de lo dispuesto en el inciso $1^{\circ}$ del artículo 124 del Código Tributario. Así, el que no se haya practicado una Liquidación en este caso-según afirma el recurrente, pero no se ha establecido como hecho cierto en el fallo- sólo importa una abstención del Servicio para el cobro de las diferencias de impuestos que podrian derivarse del mismo contenido de la Resolución-abstención que incluso podría tener el carácter de definitivo de haberse cumplido los plazos de prescripción aplicables al caso-, pero que no conlleva aceptar tácitamente entonces que el contribuyente determinó correctamente su resultado tributario del periodo abordado en la resolución, que es lo que en definitiva impedia acceder a la devolución pretendida" (cons. $6^{\circ}$ ).

\section{FACULTADES DEL TRIBUNAL TRIBUTARIO Y ADUANERO PARA PONDERAR LOS ANTECEDENTES NO PRESENTADOS POR EL CONTRIBUYENTE DURANTE LA FISCALIZACIÓN ADMINISTRATIVA DEL SERVICIO DE IMPUESTOS INTERNOS}

En el período en examen la Corte Suprema ha mantenido su jurisprudencia por la cual rechaza las restricciones que el Servicio de Impuestos Internos propugna - no derivadas de lo prescrito en el artículo 132, inciso $11^{\circ}$, del Código Tributario-, a la actividad jurisdiccional llevada a cabo por los Tribunales Tributarios, tesis de acuerdo a la que éstos se encuentran limitados en su competencia a los antecedentes de hecho y de derecho tenidos en cuenta por el mismo Servicio para la dictación del acto reclamado, límites que se transgreden al ponderar para resolver el reclamo otros elementos probatorios presentados en alguna de las instancias del proceso jurisdiccional.

Al respecto, ha señalado la Corte en el Rol No 2866-2015 de 21 de abril de 2016 que "la sede jurisdiccional dista de ser una 'segunda revisión' de los antecedentes presentados a la administración, comprensión que se ve ratificada al analizar las disposiciones de excepción que coartan las posibilidades probatorias de las partes, sujetas previamente a la acreditación de precisos y determinados supuestos por parte de la administración, como lo es la contenida en el inciso $11^{\circ}$ del artículo 132 del Código Tributario. Así, entonces, los tribunales del grado han de emitir su dictamen sobre todos $y$ cada uno de los asuntos propuestos por las partes, de acuerdo a las normas procesales aplicables al caso, dictando sentencia estableciendo los hechos de la causa, sobre la base de la prueba rendida, aplicando el derecho pertinente, lo que ha de ser revisado por el tribunal ad quem de acuerdo a la distribución de competencias propia de los recursos que involucran instancia, de manera 
que la restricción funcional que propone el reclamado no se condice con la función asignada por la Constitución y las leyes a los tribunales de justicia, por lo que no hay error de derecho -y menos de carácter sustancial-al haber sido decidida la litis de acuerdo a los hechos y el derecho planteado en las fases procesales correspondientes" (cons. $\left.7^{\circ}\right)^{11}$.

\section{Deber de fundamentación EN MATERIa TRIBUTARIA DISTINTO AL DEL CONTENCIOSO GENERAL}

La Corte Suprema ha continuado afirmando la obligación del Servicio de Impuestos Internos de fundamentar sus actuaciones administrativas que incidan en las solicitudes de los administrados, en particular, aquellas en que se deniega la devolución de los Pagos Provisionales Mensuales pagados o del IVA Exportador.

Así en el Rol N 6345-15 de 25 de abril de 2016 expresa "Que el cuerpo legal antes citado [Ley $\mathrm{N}^{\circ}$ 19.880], dictado en el año 2003, al establecer que los actos administrativos deben expresar los hechos y fundamentos de derecho $y$ que la decisión contenida en una resolución debe ser fundada, recoge normativamente la necesidad de que éstos cuenten con la debida motivación, cuestión que la doctrina y jurisprudencia judicial y administrativa habia venido desarrollando latamente. En efecto, antes de su dictación ya se sostenía que 'no obstante no haber una ley general que precise en forma sistemática cuáles actos administrativos deben especialmente motivarse, de diversos preceptos constitucionales, relacionados con la participación de particulares y la garantía a un racional y justo procedimiento que afecte las situaciones o derechos de terceros, debe contener en su texto los fundamentos de hecho y de derecho que le sirven de justificación', y se reafirmaba manifestando que 'la jurisprudencia administrativa exige que los actos administrativos se basten a si mismos y que el texto que los contiene indique, las razones de hecho y de derecho que son su sustento y apoyo', haciendo sin duda alusión al Dictamen 33.066 de la Contraloría General de la República, de 1984. (Aróstica Maldonado, U. de Chile, 'La motivación de los actos administrativos en el Derecho Chileno', 1986). Es asi como, en la actualidad, se entiende que uno de los elementos básicos o constitutivos del acto administrativo, es su fundamentación, la que está dada por la expresión formal de la situación de hecho-motivo, ligado a una necesidad pública que hay que satisfacer-y la explicitación de las razones o fundamentos que han llevado a la Administración a adoptar ante tal hecho, una determinada decisión, que es la que se enuncia o declara. En definitiva,

${ }^{11}$ Esta reflexión reproduce en idénticos términos lo postulado por la Corte en su sentencia dictada en el Rol No 11.461-14 de 15 de abril de 2015. 
es la explicitación formal de la justificación de la decisión y ella comprende tanto los hechos como las razones que mueven juridicamente a adoptarla. Se agrega que no basta con fórmulas convencionales, sino que deben ser razones suficientes, capaces de dar cuenta del camino lógico o racional seguido para llegar a la decisión, lo que implica, en consecuencia, que ha de ser congruente (Soto Kloss, Eduardo, Derecho Administrativo, Temas Fundamentales, pág. 368 y ss.) Asimismo, la jurisprudencia de nuestros tribunales ha sido constante y homogénea en el sentido de exigir la debida fundamentación del acto de autoridad, entendiendo que está viciado cuando hay ausencia de hechos que expliquen la decisión, o se prescinde de los razonamientos que conducen a la decisión" (cons. 5). En el mismo orden, en el Rol No 36.489-15 de 24 de octubre de 2016 se sostuvo que las razones para denegar la devolución pretendida por el contribuyente "deben explicitarse en la resolución denegatoria, pues de otro modo, se dejaría a la absoluta arbitrariedad de un órgano de la Administración acceder o no a la devolución solicitada y, por otra parte, al no bastarse a si misma la resolución, impediría al contribuyente ejercer su derecho a reclamar en su contra al desconocer sus fundamentos" (cons. $3^{\circ}$ ), citando igual declaración efectuada en el Rol No 9432-15 de 24 de mayo de 2016.

Sin embargo en la sentencia dictada en la causa Rol No 9966-2015 de 12 de julio de 2016, la Corte delimita los alcances de esa exigencia de fundamentación, al precisar que "no resulta exigible al ente fiscalizador la utilización de una nomenclatura propia del contencioso administrativo general, puesto que debe atenderse a las caracteristicas especiales de esta rama del derecho, de tal forma que los conceptos contables son la mayoría de las veces necesarios y más ilustrativos que las expresiones jurídicas. Por tal razón, la exigencia de fundamentación que se haga a una resolución dictada por el Servicio de Impuestos Internos debe atender las particulares caracteristicas dadas por la especialidad de la materia sujeta a su control' (cons. $3^{\circ}$ ). Reitera con ello lo declarado en la causa Rol No 16.588-2014 de 5 de mayo de 2015 .

Posteriormente, la Corte, al haber sido invocada la sentencia recién mencionada por el recurrente -el Servicio de Impuestos Internos- en favor de la tesis por él esgrimida, aclara que "en la sentencia dictada por esta Corte citada por el recurrente en sus alegatos (SCS Rol $N^{\circ} 16.588-14$ de 5 de mayo de 2015), no se declara que la resolución que deniega una devolución pueda carecer de fundamento, sino que al entregar dicha fundamentación 'no resulta exigible al ente fiscalizador la utilización de una nomenclatura propia del contencioso administrativo general (...) Pues bien, como ya se ha expuesto, en el caso sub judice, no se cuestionó por los jueces de la instancia que el Servicio haya utilizado en la resolución reclamada 'conceptos contables', códigos de observaciones -como es usual-, u otros términos técnicos análogos propios de la práctica tributaria, sino derechamente que 'carece de la motiva- 
ción necesaria para sustentar la decisión que contiene', sea que para expresar dicha motivación el Servicio se haya valido de la nomenclatura propia del contencioso administrativo general o de la especial del área contable y tributaria ajena generalmente a los administrados. Es decir, aun de haber contado el contribuyente de estos autos con conocimiento en dichas materias, igualmente no podría discernir cuál es el motivo concreto por el cual se le deniega la devolución, ya que no se da ningún indicio en la Resolución reclamada de cuáles son las 'inconsistencias'-ni siquiera a través de códigos-que el Servicio habria advertido en la declaración de renta del contribuyente en virtud de la cual éste pide esa devolución" (cons. $7^{\circ}$ ).

En otro orden ideas, conviene detenerse en esta sección a analizar si la suficiencia de fundamentación corresponde o no a una cuestión de hecho que debe sólo ser dilucidada por los jueces de la instancia en el proceso, caso aquél en el que la Corte Suprema sólo podría revisar tal determinación si al efectuarla los sentenciadores quebrantaron alguna norma reguladora de la prueba. En ese sentido, la Corte declaró en la causa Rol Nº 36.48915 de 24 de octubre de 2016 que, en el caso ahí tratado, "en el recurso no se postula que la Resolución reclamada que deniega la devolución pretendida por el contribuyente pueda carecer de fundamento, sino que las expresiones que contiene dicha actuación son suficientes para revestir de la motivación legalmente exigible a lo que allí se resuelve, atendida la especial naturaleza de que se trata. Como se advierte, en verdad lo reprochado por el recurso es la conclusión a la que arriban los sentenciadores luego de examinar y sopesar la densidad explicativa de la Resolución practicada por el Servicio, conclusión que al ser el resultado de la valoración y apreciación de los antecedentes y pruebas aportados por las partes conforme a las reglas de la sana critica, no puede ser desatendido o controvertido por esta Corte en esta sede de casación, a menos que se demuestre la vulneración de alguna regla de la sana crítica -u otra norma reguladora de la prueba-con influencia sustancial en lo dispositivo del fallo". Este criterio ya había sido desarrollado en iguales términos en el Rol $\mathrm{N}^{\circ}$ 15.301-14 de 21 de julio de 2015.

De ese modo, la Corte declara que discernir si la motivación que entrega la actuación cuestionada cumple el estándar requerido legalmente $y$, por ende, si se vulneran al no poseerlo las normas que demandan su fundamentación, es parte de la labor de ponderación de la prueba que deben realizar los magistrados del grado y, por tanto, únicamente revisable por vía casacional en caso de quebrantarse alguna norma reguladora de la prueba ${ }^{12}$.

12 Sin embargo, aparece como excepción a los criterios reseñados lo expresado en el Rol N $16.588-2014$ de 5 de mayo de 2015 y en el Rol No 9966-2015 de 12 de julio de 2016, en los que no sólo se desestima la aplicación de los artículos 11 y 41 de la Ley $\mathrm{N}^{\circ} 19.880$ para la fundamentación de la Resolución del Servicio de Impuestos 


\section{IMPROCEDENCIA DEL DECAIMIENTO EN EL JUICIO DE} RECLAMACIÓN

La Corte Suprema en diversos fallos ya había explicado las razones por las que la aplicación de la institución del decaimiento no resultaba procedente en el procedimiento ejecutivo de cobro reglado en el Título V del Libro II del Código Tributario, esencialmente, dado el carácter jurisdiccional y no administrativo de dicho procedimiento ${ }^{13}$.

En el año 2016 la Corte efectúa un ejercicio similar de fundamentación para desestimar la alegación de decaimiento realizada por el contribuyente en un procedimiento general de reclamación seguido ante el Director Regional del Servicio de Impuestos Internos, al considerar que el carácter jurisdiccional de este procedimiento hacía improcedente la aplicación de dicho instituto ${ }^{14}$. Al respecto, señala en la causa Rol No $1928-15$ de 10

Internos, como cuestión de derecho propia del ámbito del recurso de casación, sino que además se pronuncia sobre la suficiencia de esa motivación, concluyendo, luego de reproducir el contenido de las respectivas actuaciones que "En esas circunstancias, aparece que la fundamentación de dicho acto, al tenor de las exigencias contenidas en el Código Tributario, es suficiente para su adecuada inteligencia sin dejar en la indefensión al contribuyente" (cons. $4^{\circ}$ de ambos fallos), con lo cual la Corte realiza una labor de ponderación del contenido de las Resoluciones del Servicio impugnadas por el reclamante, a la luz de la materia y operaciones fiscalizadas.

${ }^{13}$ Rol No $27.825-16$ de 5 de septiembre de 2016 y Rol No 28.371-16 de 20 de septiembre de 2016. En el Rol No 16.619-16 de 29 de diciembre de 2016, sin perjuicio de indicar que la resolución impugnada no ostenta la naturaleza de aquellas contra las cuales resulta procedente el recurso de casación, igualmente resalta el carácter jurisdiccional de la función del Tesorero. En el Rol No 7101-14 de 5 de agosto de 2014 y en el Rol No 24.991-14 de 12 de mayo de 2015, se rechaza la aplicación de la institución del decaimiento por defectos formales del recurso, como no haber sido alegado en las instancias, y por no haber ejercido las herramientas procesales e institutos sustantivos que habrían permitido al demandado poner término al procedimiento de ejecución y obtener la extinción de la deuda. Los dos primeros fallos citados, dictados por la Segunda Sala de la Corte Suprema, importan un cambio de criterio en esta materia al sostenido antes por la Tercera Sala del mismo Tribunal, la que estimó procedente la aplicación del decaimiento en el procedimiento de cobro ejecutivo seguido ante el Servicio de Tesorería. Así en los fallos Rol No 8420-2009 de 26 de agosto de 2011, Rol No 1308-2010 de 2 de abril de 2012, Rol No 49502010 de 17 de abril de 2012, Rol No 2577-2012 de 11 de mayo de 2012 y Rol No 1205-2010 de 25 de mayo de 2010 declaró que el decaimiento como los principios de derecho administrativo consagrados en la Ley $\mathrm{N}^{\circ} 19.880$ resultaban aplicables en el procedimiento comentado.

${ }^{14}$ En las sentencias dictadas en las causas Rol No 7135-12 de 1 de julio de 2013, Rol No 1316-13 de 30 de septiembre de 2013, Rol No 9276-12 de 17 de marzo de 2014 y Rol No 3934-13 de 22 de abril de 2014, la Corte Suprema rechaza la 
de mayo de 2016 que "los Directores Regionales del Servicio de Impuestos Internos-sin perjuicio que su función principal es administrativa-, al conocer y resolver, en primera o única instancia, conflictos jurídicos derivados de las reclamaciones deducidas por los contribuyentes y de las denuncias por infracción a las disposiciones tributarias, son tribunales que actúan en ejercicio de la jurisdicción que la ley les ha confiado, como lo autoriza expresamente el sistema constitucional y orgánico nacional. Ello, por cuanto la jurisdicción supone el poder deber que tienen los tribunales para conocer y resolver, por medio del proceso y con efecto de cosa juzgada, los conflictos de intereses de relevancia jurídica que se promuevan en el orden temporal dentro del territorio de la República y en cuya solución les corresponda intervenir (...) Que, asentado lo anterior, esto es, que la función que desempeña el Director Regional del Servicio de Impuestos Internos al resolver la reclamación formulada por un contribuyente contra una liquidación practicada por funcionarios del mismo Servicio es de carácter jurisdiccional y no administrativo y, que, por consiguiente, el procedimiento mediante el cual y en el cual ejerce dicha función reviste el mismo carácter jurisdiccional, no ha podido aplicarse al mismo el artículo 14 de la Ley $N^{\circ} 19.880$ que consagra la 'desaparición sobreviniente del objeto del procedimiento'-que la sentencia revisada asimila al 'decaimiento del procedimiento administrativo'-, pues como disponen los articulos 1 y 2 de ese mismo texto legal, esa ley establece y regula las bases del 'procedimiento administrativo' de los actos de la 'Administración del Estado', y, además, las disposiciones de esa ley sólo son aplicables a los ministerios, las intendencias, las gobernaciones y los servicios públicos creados para el cumplimiento de la 'función administrativa', junto a la Contraloria General de la República, a las Fuerzas Armadas y a las Fuerzas de Orden y Seguridad Pública, a los gobiernos regionales y a las municipalidades. De ese modo, la función jurisdiccional que ejerce el Director Regional del Servicio en el procedimiento general de reclamaciones previsto en el Título II del Libro III del Código Tributario, no se gobierna por la Ley $N^{\circ} 19.880$, ni siquiera de manera supletoria, motivo por el cual yerran los sentenciadores de segundo grado al ponerle término en base a las normas especiales que contempla ese cuerpo legal' (cons. $7^{\circ}$ y $8^{\circ}$ ).

\section{RENTA PERCIBIDA-DEVENGADA}

La Corte Suprema, en la causa Rol N $37.180-15$ de 24 de octubre de 2016 ratifica su criterio expuesto antes en el Rol No 1826-13 de 21 de

aplicación del decaimiento en el procedimiento general de reclamación, por estimar que ello importó una aplicación analógica de los artículos 200 y 201 del Código Tributario, sin detenerse en el análisis del carácter jurisdiccional del procedimiento. 
octubre de 2013, por el cual los intereses que obtiene el contribuyente por depósitos a plazo renovables son percibidos una vez cumplido el plazo por el cual fueron tomados, no obstante que al no ser liquidados se produzca su renovación y, por ende, deben declararse como parte de la base imponible del Impuesto Global Complementario el año tributario respectivo.

En ese orden, la Corte expresó que los conceptos de renta devengada y renta percibida contenidos en los numerales $2^{\circ}$ y $3^{\circ}$ del artículo 2 de la Ley sobre Impuesto a la Renta, llevados al caso en análisis "conducen a concluir que los intereses pactados entre el tomador del depósito renovable y el banco captador, con independencia del momento en que se estimen devengados - al tomar el depósito o al vencimiento del mismo-, se perciben una vez que acaece el vencimiento acordado, momento en que dichos intereses ingresan al patrimonio del depositante, de manera que éste puede optar por retirarlos junto con el capital invertido o volver a invertirlos, como ocurrió en el caso sub lite. Nada más repárese que si las sumas correspondientes a los intereses generados por el capital invertido no hubiesen ingresado materialmente al patrimonio de la contribuyente al vencimiento del plazo pactado para el depósito-como postula el recurrente-, importaría entonces que dichos montos seguían a la sazón en el patrimonio del banco depositario y, por tanto, que al momento en que la reclamante renovó el depósito incluyendo ahora esos intereses en el capital reinvertido, utilizó o dispuso de dinero ajeno perteneciente al Banco Santander para dicha operación. Huelga señalar que este postulado es, conforme a las normas antes examinadas, inaceptable (...) Que, por otra parte, lo planteado por el recurso erróneamente iguala el tratamiento tributario que cabe dar a los depósitos a plazo con el correspondiente a los fondos mutuos -como se sostiene expresamente en el libelo a fs. 88-, pasando por alto que en el caso de los últimos, se compran 'cuotas' del fondo, por lo que la inversión se expresa en 'valores cuota'. Asi, la variación diaria que experimente el valor cuota del fondo irá determinado la ganancia o pérdida que se obtenga por invertir en dicho fondo mutuo y, por lo tanto, necesariamente sólo al efectuarse el 'rescate', y en la medida que exista una utilidad en el retiro, esto es, que el valor cuota al cual se rescató sea superior al cual se invirtió, surge la obligación de declararla y tributar. Al contrario, en los depósitos a plazo como el de estos antecedentes, con cada vencimiento, sin importar su renovación automática, se determina con certeza la utilidad percibida por el inversionista y, por ende, los intereses tributan independientemente de que se rescate o liquide o no el depósito" (cons. $5^{\circ}$ y $6^{\circ}$ ).

\section{Peculio profesional IndUStRIAL}

En la sentencia dictada en la causa Rol No $35.495-15$ de 14 de sep- 
tiembre de 2016 la Corte Suprema rechaza el recurso de casación interpuesto por el curador de varios menores de edad contra la Resolución del Servicio de Impuestos Internos que rechazó la devolución pedida por éstos, sosteniendo que no se había acreditado que los derechos sociales que permitieron el retiro de utilidades de las respectivas sociedades, hubiesen sido adquiridos con el peculio profesional o industrial desarrollado por los menores y, dado que al curador sólo se encargó la administración de lo que de aquello proviniere, tales utilidades retiradas deben formar parte de la base imponible de quien tenga la patria y potestad.

En ese orden la Corte expresó que "de esa manera, si en el caso sub lite el reclamante arguyó que los retiros de las sociedades en que participan los menores adultos que representa su curador especial, forman parte de su peculio profesional o industrial, entonces debió demostrar en el juicio que los derechos sociales que les dieron derecho a los retiros, tienen su origen en el trabajo de los menores en cuestión, única manera de considerar esos retiros como 'frutos' de los bienes adquiridos con su peculio profesional. Pues bien, esto último fue expresamente descartado por la sentencia impugnada, la que estableció en su razonamiento $11^{\circ}$ que las rentas generadas a partir de las participaciones sociales, por la vía de retiros, no son en modo alguno fruto del trabajo profesional o industrial, no existiendo en autos ningún otro antecedente en que conste que los menores desarrollan alguna actividad de aquellas que representan el peculio profesional o industrial'. Respecto de estos hechos, el recurrente no sostiene que éstos hayan sido establecidos por los jueces de la instancia con infracción de alguna norma reguladora de la prueba, por lo que debe estarse a ellos en el análisis de las alegaciones del recurso, de lo cual aparece con claridad que éste se basa en hechos contrarios a los fijados en el fallo y sin los cuales el mismo no puede ser acogido, ya que, si bien los menores adultos pueden tener participación en sociedades e incluso los frutos de esa participación puede formar parte de su peculio profesional o industrial, esto último sólo se presentará si los derechos sociales fueron adquiridos con dineros provenientes del trabajo de los menores -pasando esos derechos a formar parte del peculio-, unica manera en que, a su vez, puede considerarse los retiros como frutos provenientes de esos bienes adquiridos y, por ende, también integrantes del peculio profesional (...) Que la circunstancia de que se haya designado un curador especial respecto de los menores de autos para cumplir labores de carácter administrativo o de supervigilancia que no incluyen la facultad de administración de ingreso alguno que corresponda a las utilidades de los bienes de los menores (asi se establece en el considerando $8^{\circ}$ del fallo) no obsta, sino confirma lo que se viene explicando, al disponer el artículo 439 del Código Civil que 'El menor que está bajo curaduría tendrá las mismas facultades administrativas que el hijo sujeto a patria potestad, respecto de los bienes adquiridos por él en el ejercicio 
de un empleo, oficio, profesión o industria', es decir, sea que el menor esté o no bajo curaduría, sólo formaran parte de su peculio profesional o industrial los bienes 'adquiridos por él en el ejercicio de un empleo, oficio, profesión o industria', circunstancias que como ya se ha dicho, no se han sentado como ciertas en esta causa (...) Que, entonces, atendido que los derechos sociales no fueron adquiridos por los menores con su trabajo-como expresamente demanda el artículo $250 N^{\circ} 1$ del Código Civil para excluirlos de la patria potestad de sus padres- $y$, por ende, no forman parte de su peculio profesional o industrial, el o los padres -según sea el caso-que tenga la patria potestad conservan el usufructo legal sobre esos derechos sociales y, por ende, el derecho a gozar de los frutos de esos derechos - los retiros en este caso-. En definitiva, por aumentar esos retiros el patrimonio de quien o quienes detenten la patria potestad, deben ser éstos y no los menores a través de su curador especial, quienes incluyan esas sumas en su declaración anual de impuestos a la renta" (cons. $4^{\circ}, 5^{\circ}$ y $6^{\circ}$ ).

\section{FALlos CiTADOS}

Rol N 1917-06 de 5 de septiembre de 2006, "Serviu Tarapacá con Luis Ojeda Moscoso".

Rol No 8420-09 de 26 de agosto de 2011, "Fisco de Chile con Páez Pelayo Esteban".

Rol No 4950-10 de 17 de abril de 2012, “Tesorería Regional de Antofagasta con González Olivares Alberto".

Rol No 1205-10 de 25 de mayo de 2010, “Tesorería Regional de Antofagasta con Yáñez Iriarte, Marisel”.

Rol No 1308-10 de 2 de abril de 2012, “Tesorería Regional de Antofagasta con Flota Barrios S.A."

Rol N²676-11 de 10 de junio de 2011, "Inmobiliaria Pazam Ltda. contra Alcalde de la I. Municipalidad de Las Condes".

Rol No 2577-12 de 11 de mayo de 2012, "Tesorería Regional de Aisén con Benjamín Alan Rossel Vargas".

Rol No 7135-12 de 1 de julio de 2013, "Maderera Fénix Ltda. con S.I.I."

Rol No 9276-12 de 17 de marzo de 2014, "Cont. Alfaro González y Cía. Ltda. con S.I.I.”

Rol No 1316-13 de 30 de septiembre de 2013, "Serv. Com. San Sebastian S.A. con S.I.I.”

Rol N 1826-13 de 21 de octubre de 2013, "Gonzalo Francisco Bofill Velarde con S.I.I."

Rol N ${ }^{\circ}$ 5165-13 de 14 de abril de 2014, "Industral Molina Ltda. con S.I.I." 
Rol No 3934-13 de 22 de abril de 2014, "Soc. Industrial Textil Formosa Ltda. con S.I.I.”

Rol Nº 6879-13 de 21 de julio de 2014, "Empresa Pesquera Eperva S.A. con Servicio de Impuestos Internos".

Rol No 16.013-13 de 20 de agosto de 2014, "Claudio Sergio Santelices Boettcher con S.I.I. Direc. Regional Concepción”.

Rol No 49.683-13 de 17 de agosto de 2016, "Venegas Morvan Juan Ramón con Tesorería General de la República".

Rol No 7101-14 de 5 de agosto de 2014, "Fisco de Chile con Figueroa Tocornal Jaime".

Rol No 32.094-14 de 13 de abril de 2015, "Tesorería General de la República con Clínica Central S.A.”

Rol N ${ }^{\circ} 11.461-14$ de 15 de abril de 2015, "Club Deportes Naval S.A.D.P. con S.I.I. Direc. Regional Concepción”.

Rol No 16.588-14 de 5 de mayo de 2015, "Sociedad Constructora El Arrayán Ltda. con S.I.I. IX Direccion Regional”.

Rol No 24.991-14 de 12 de mayo de 2015, “Tesorería General de la República con Suazo Esparza Manuel Jesús".

Rol N 13.387-14 de 18 de mayo de 2015, "Comercial Hual Ltda. con S.I.I."

Rol N² 21.647-14 de 10 de junio de 2015, "Hormazabal Calderón Hugo con S.I.I."

Rol No 15.301-14 de 21 de julio de 2015, "Samsung Electronics Chile Ltda. con Servicio Nacional de Aduanas".

Rol No 23.544-14 de 18 de agosto de 2015, "Zúñiga Maulen Manuel Eduardo con S.I.I. XVI Dir. Santiago Sur”.

Rol No 27.319-14 de 18 de agosto de 2015, "Sps Inmobiliaria E Inversiones S.A. con S.I.I. Santiago Poniente".

Rol No 16.644-14 de 10 de septiembre de 2015, "Distribuidora Don Francis S.A. con S.I.I."

Rol No 32.359-14 de 4 de noviembre de 2015, "Clínica de Especialidades Médicas S.A. con S.I.I., Dirección Regional de Antofagasta”.

Rol N 6280-15 de 27 de mayo de 2015, "Agrícola Bianchi Becker Ltda. con S.I.I."

Rol No 1115-15 de 29 de diciembre de 2015, "Maquinarias Lillo Ltda. con S.I.I., Direc. Regional Concepción".

Rol No 3319-15 de 17 de marzo de 2016, "Nespresso Chile S. A. con S.I.I."

Rol No 2866-15 de 21 de abril de 2016, "Asesorías e Inversiones Ritoque Ltda. con S.I.I." 
Rol N 6345-15 de 25 de abril de 2016, “Administradora de Supermercados Hiper Limitada con S.I.I. La Serena”.

Rol N 1928-15 de 10 de mayo de 2016, "Gloria P. Sabugo Canseco con S.I.I."

Rol No 9432-15 de 24 de mayo de 2016, "Exportadora Pacífico Sur Ltda. con S.I.I. VII Dirección Regional Talca".

Rol N 9966-15 de 12 de julio de 2016, "Leonardo Antonio García Sabugal con S.I.I. IX Direccion Regional”.

Rol No 35.495-15 de 14 de septiembre de 2016, "Andrighetti Márquez Tomás, Andrighetti Márquez María, Andrighetti Márquez Martín con S.I.I."

Rol No 26.914-15 de 22 de septiembre de 2016, "Comercializadora Andina S.A. con S.I.I."

Rol N 18.136-15 de 12 de octubre de 2016, "Feria Ganaderos Osorno S.A. con S.I.I."

Rol No 36.489-15 de 24 de octubre de 2016, "Agencia de Aduanas Waldemar Adelsdorfen y Cía. Ltda. con S.I.I. V Dr. Valparaíso”.

Rol No 37.180-15 de 24 de octubre de 2016, "Peñaloza Eyraud Eliana Victoria con S.I.I.”

Rol N²6.905-15 de 28 de noviembre de 2016, "Instituto de Normalizacion Previsional con S.I.I."

Rol N 37.181-15 de 29 de noviembre de 2016 ,"Alid Aleuy Ricardo con S.I.I."

Rol N ${ }^{\circ} 11.852-15$ de 6 de diciembre de 2016, "NAI International Inc. con S.I.I."

Rol N ${ }^{\circ}$ 12.874-15 de 7 de diciembre de 2016, "Feria Ganaderos Osorno S.A. con S.I.I."

Rol N $\mathrm{N}^{\circ}$ 35.496-15 de 12 de diciembre de 2016, "Inversiones Macul S.A. con S.I.I.”

Rol N 14.993-16 de 28 de marzo de 2016, “Zilic Iván Alejandro con Tesorería General de la República”

Rol N 5379-16 de 28 de marzo de 2016, "Elgueta y Elgueta Limitada con Tesorería General de la República”.

Rol N 16.285-16 de 28 de marzo de 2016, "Alvarez Muñoz, Gonzalo Osvaldo con Fisco de Chile".

Rol No 16.353-16 de 28 de marzo de 2016, "Assad Castelli Mara Soledad con Tesorería General de la República”.

Rol N 45.877-16 de 8 de agosto de 2016, "Díaz Pino Mario Enrique con Tesorería General de la República”.

Rol No 27.825-16 de 5 de septiembre de 2016, "Tesorería General de la República con Espinoza Otto Jorge Eduardo”. 
Rol N² 28.371-16 de 20 de septiembre de 2016, "Tesorería Regional de Antofagasta con Mancilla Olivares Daniel".

Rol No 41.099-16 de 26 de diciembre de 2016, "Fisco-Tesorería Regional Metropolitana con Isapre Ferrosalud S.A.”

Rol No 28.604-16 de 28 de diciembre de 2016, "Tesorería Regional de Aysén con Andrade Quenti Margarita”.

Rol No 52.954-16 de 28 de diciembre de 2016, "Servicio de Tesorerías con Servicios Cidef S.A."

Rol No 16.619-16 de 29 de diciembre de 2016, "Fisco-Tesorería Regional con Ferrada Valenzuela Luis Valentínn". 
